\title{
IMPACT OF SOCIO-DEMOGRAPHIC CHARACTERISTICS AND LONG-TERM COMPLICATIONS ON QUALITY OF LIFE IN PATIENTS WITH DIABETES MELLITUS
}

\author{
Miodrag Stojanović ${ }^{1,2}$, Goran Cvetanović3 ${ }^{3}$ Marija Anđelković-Apostolović1,2, Dijana Stojanović1, Nataša Rančić1,4 \\ ${ }^{1}$ University of Niš, Faculty of Medicine Niš, Niš, Serbia \\ ${ }^{2}$ Department of Biostatistics, Institute for Public Health, Niš, Serbia \\ ${ }^{3}$ General Hospital of Leskovac, Leskovac, Serbia \\ ${ }^{4}$ Centre for Control and Prevention of Diseases, Institute of Public Health, Niš, Serbia
}

\section{SUMMARY}

Objective: Diabetes mellitus (DM) has been one of the leading chronic diseases worldwide over past decades. The objective of the study was to identify predictors associated with health-related quality of life (HRQOL) in diabetic patients.

Methods: A cross-sectional questionnaire-based study was conducted at the General Hospital of the city of Leskovac, between June and November 2015. The Short Form-36 (SF-36) questionnaire, EuroQol-5D (EQ-5D) and EuroQol-VAS (EQ-VAS) questionnaires were used. Univariate and multivariate linear regression analyses were performed.

Results: The total number of patients was 285,112 men (39.3\%) and 173 women (60.7\%), average age $63.92 \pm 1.07$ years. The results of multiple linear regression of socio-demographic characteristics in relation to dimensions of the quality of life measured by SF-36 and EQ-VAS showed that age, country (rural) life, low level of education, retirement, and poor economic status are predictors of lower quality of life. Our results showed that employment has a significant association with higher Physical Component Score (PCS), Mental Component Score (MCS) and EQ-VAS score, which can be explained with higher incomes, improved economic status and less possibility for the occurrence of depressive mood. Patients without formal education have lower QOL. Univariate multiple regression analysis of the presence of micro- and macrovascular complications of DM showed that angina pectoris, heart failure, diabetic retinopathy, and diabetic nephropathy are the most important factors affecting the quality of life in our population. After including the multivariate model, all tested complications remained statistically significant.

Conclusion: Our results showed that both socioeconomic and chronic complications are relevant factors of HRQOL in type 1 and 2 diabetes mellitus patients. Age, rural lifestyle, retirement, lower level of education and low socioeconomic status, as well as DM complications (angina pectoris, hearth failure, diabetes nephropathy, and diabetes retinopathy) were found to be independent risk factors for the component scores of SF-36 and EQ-VAS score. Taking into consideration the results obtained, health practitioners should be aware not only of the clinical parameters of patients with DM, but also of their educational level and working status.

Key words: diabetes mellitus, health-related quality of life, complications, SF-36, EuroQol-5D, EuroQol-VAS

Address for correspondence: N. Rančić, Centre for Disease Control and Prevention, Institute of Public Health, Niš, Bulevard Dr Zoran Đinđić 50, 18000 Niš, Serbia. E-mail: drrancicnatasa@gmail.com

https://doi.org/10.21101/cejph.a5022

\section{INTRODUCTION}

Diabetes mellitus (DM) has been one of the leading chronic diseases worldwide over past decades. The World Health Organization (WHO) estimates that the number of diabetic patients will grow up to 366 million by 2030 (1). Among factors contributing to the increasing incidence of DM are sedentary lifestyle, obesity, and population ageing. DM complications increase morbidity and mortality, and consequently decrease the health-related quality of life (HRQOL). Hence, the complications affect physical and mental functioning and patients' well-being, as well as healthcare costs of each country.

Previous studies have emphasized poorer quality of life (especially physical health) in diabetic patients compared to the general population (2-5). Factors associated with lower quality of life in diabetics are older age, female gender, lower economic status, lower educational level, a lack of physical activity, and chronic macro- and microvascular diabetic complications (6-10). Macrovascular complications such as cardiovascular, cerebrovascular and peripheral vascular disease result in physical disability and decreased HRQOL in these patients. A number of studies have shown that microvascular complications such as nephropathy, retinopathy and diabetic foot play a crucial role in patients' decreased physical and mental well-being (11-14). Lower health-related scores are associated with these conditions.

We consider both socioeconomic status and clinical complications very important for HRQOL of diabetics. 
The objective of the study was to identify predictors associated with HRQOL of diabetic patients which can be modified in the future to improve patients' life quality.

\section{MATERIALS AND METHODS}

A cross-sectional study was conducted among diabetic patients at the General Hospital of the city of Leskovac, Serbia, from June to November 2015. The respondents were selected during their routine visits to doctor for irregular laboratory control. All patients signed written consent and then were interviewed by a trained interviewer using an approved protocol and patient's clinical record form.

The inclusion criteria were: patients suffering from type 1 and 2 diabetes mellitus with a known disease duration, respondents of both sexes over 18 years of age, both with and without diabetes complications.

The excluding criteria were: respondents younger than 18 , newly discovered diabetes mellitus patients, patients who have other chronic diseases (rheumatic, oncological, pulmonary, gynaecological, urologic, and mental) that were not the result of diabetes.

\section{Instruments}

The questionnaire consisted of two parts. The first part included socio-demographic characteristics such as sex, age, place of residence, education level, employment status, marital status, and economic status. According to economic status based on the monthly household income, the patients were classified into poor, fair, good, or very good categories. Clinical data were collected from patients' electronic medical records. The second part included generic questionnaires: Short Form-36 (SF-36) (15), EuroQol-5 Dimension (EQ-5D) (16), and EuroQol-VAS (EQ-VAS) (17), which are widely used for measuring health status among diseased people.

Serbian version of the Medical Outcomes Short Form-36 (SF36) was used. It included 36 questions divided into eight health dimensions: physical functioning (PF), social functioning, (SF), role limitation due to physical functioning (RE), bodily pain, mental health $(\mathrm{MH})$, role limitation due to emotional problems (RE), vitality and general health perception $(\mathrm{GH})$. Each item was scored from 0 (worst well-being) to 100 (best well-being). After this, summary scores such as Physical Component Score (PCS) and Mental Component Score (MCS) were calculated according to the standard procedure, where higher level scores indicate higher quality of life.

The EuroQol-5 Dimension is a standardized measure of health status developed by the EuroQoL Group in order to provide a simple, generic measure of health for clinical and economic appraisal. EQ-5D is designed for self-completion by respondents and is ideally suited for use in postal surveys, in clinics, and in face-to-face interviews. The EQ-5D descriptive system comprises the following 5 dimensions: mobility, self-care, usual activities, pain/discomfort, and anxiety/depression. Each dimension has 3 levels: no problems, some problems, severe problems. The respondent is asked to indicate his/her health state by ticking (or placing a cross) in the box against the most appropriate statement for each of the 5 dimensions. This decision results in a 1-digit number expressing the level selected for that dimension. The digits for 5 dimensions can be combined in a 5-digit number describing the respondent's health state. It should be noted that the numerals 1-3 have no arithmetic properties and should not be used as a cardinal score.

The EQ Visual Analogue Scale records the respondent's selfrated health on a vertical, visual analogue scale where the endpoints are labelled 'best imaginable health state' and 'worst imaginable health state'. This information can be used as a quantitative measure of health outcome as judged by individual respondents.

\section{Statistical Analysis}

Statistical analysis was performed using the SPSS software package 20. Data are presented as percent frequency or mean \pm standard deviation (SD). Linear univariate regression analysis was used to find association between socio-demographic characteristics and diabetes complications on health related quality of life (PCS, MCS and EQ-5D VAS). The results are presented as Beta coefficients and its p-value. Statistically significant parameters were then included in the multivariate model. Statistical significance was accepted when the corresponding p-value was less than 0.05 .

\section{RESULTS}

Our study population included 285 participants with a mean age $63.92 \pm 1.07$ years; $112(39.3 \%)$ were men and $173(60.7 \%)$ women. Diabetes mellitus type II was recorded in 245 (85.9\%) patients, while type I was present in $40(14.1 \%)$ patients. The average duration of disease was $10.59 \pm 15.6$ years. A slightly higher number of respondents live in the rural areas - 151 (53.0\%), while $134(47.0 \%)$ of respondents live in the city.

The socio-demographic characteristics of the study population are presented in Table 1 and complications related to diabetes in Table 2.

The results of univariate linear regression analysis of sociodemographic factors related to Physical and Mental Composite Scores, and to EQ-5D VAS score are presented in Table 3. Among the socio-demographic factors, age, living place, lack of formal education, pre-university education, employment, retirement, and poor economic status were statistically significant in all 3 tested scores, while high school degree and good economic status were statistically significant only in PCS and MCS. Age, living in the countryside, lack of formal education, retirement, and poor economic status were connected to lower scores, while high school degree, pre-university degree and good socioeconomic status had positive impact on HRQOL. After inserting the statistically significant independent factors into multivariate models for each tested score, the statistically significant factors included age, pre-university degree and poor economic status for all 3 testing scores (Table 4).

The impact of diabetes mellitus complications on PCS, MCS and EQ-5D VAS is presented via univariate linear regression analysis in Table 5. The presence of angina pectoris, heart failure and diabetes retinopathy imposed a significant negative impact on PCS, MCS, and EQ-5D VAS, while diabetes nephropathy had impact only on PCS and EQ-5D VAS score. After inserting statistically significant complications in multivariate models for each tested score, all complications were statistically significant again (Table 6). 
Table 1. Socio-demographic characteristics of the study population $(N=285)$

\begin{tabular}{|c|c|c|c|}
\hline \multicolumn{2}{|l|}{ Variable } & $\mathrm{n}$ & $\%$ \\
\hline \multirow{2}{*}{ Sex } & Male & 112 & 39.3 \\
\hline & Female & 173 & 60.7 \\
\hline \multicolumn{2}{|l|}{ Age (mean \pm SD) } & $63.92 \pm 1.07$ & \\
\hline \multirow{2}{*}{ Type of DM } & 1 & 245 & 86.0 \\
\hline & $\|$ & 40 & 14.0 \\
\hline \multicolumn{2}{|c|}{ Duration of DM (years, mean \pm SD) } & $10.59 \pm 15.6$ & \\
\hline \multirow{2}{*}{ Place of residence } & City & 134 & 47.0 \\
\hline & Country & 151 & 53.0 \\
\hline \multirow{5}{*}{ Education } & No formal education & 74 & 26.0 \\
\hline & Primary & 62 & 21.8 \\
\hline & High school & 111 & 38.9 \\
\hline & Pre-university & 23 & 8.1 \\
\hline & University & 15 & 5.3 \\
\hline \multirow{5}{*}{ Employment } & Employed & 26 & 9.1 \\
\hline & Unemployed & 64 & 22.5 \\
\hline & Farmer & 19 & 6.7 \\
\hline & Retirement & 174 & 61.1 \\
\hline & Invalid & 2 & 0.7 \\
\hline \multirow{4}{*}{ Marital status } & Unmarried & 13 & 4.6 \\
\hline & Married & 208 & 73.0 \\
\hline & Divorced & 7 & 2.5 \\
\hline & Widowed & 57 & 20.0 \\
\hline \multirow{4}{*}{ Economic status } & Poor & 89 & 31.2 \\
\hline & Fair & 161 & 56.5 \\
\hline & Good & 31 & 10.9 \\
\hline & Very good & 4 & 1.4 \\
\hline
\end{tabular}

\section{DISCUSSION}

In this cross-sectional study, we examined the impact of socio-demographic factors and chronic complications of diabetes mellitus on the quality of life (QOL) in patients with DM type 1 and 2. The quality of life related to health status was measured using standardized evaluation systems presented by the SF36 and EQ-5D VAS questionnaires. These questionnaires are widely used as a standardized evaluation system for patients with type 2 DM in Western Europe and Asia (18). EQ-5D VAS scale was used within the EC-5D-3L questionnaire, which directly measures the assessment of the health status of patients based of their self-assessment (19).

Assessing the quality of life of patients with diabetes mellitus is a valuable topic. The number of diabetics is increasing worldwide and the consequences of DM influence not only the quality of life of these patients but also the healthcare costs. Socio-demographic characteristics of patients enrolled in our study have a significant role in the QOL since they have an impact on the outcome, the occurrence of complications and self-care, and in particular the degree of social isolation and development of depression symptoms that has been shown also in some previous studies $(20,21)$. Similar results are presented in a large Danish cross-sectional study (22) that included 2,419 patients with type 1 diabetes, which shows that poor socioeconomic conditions, age, female gender, presence of co-morbidity, poor glucoregulation, and lower level of education are associated with the appearance of depressive episodes and reduced QOL. The results of multiple linear regression of sociodemographic characteristics in relation to aspects of the quality of life measured by the SF-36 and EuroQol VAS questionnaires showed that age, country life, low level of education, retirement and poor economic status are predictors of lower quality of life. They have been proved to be important predictors for both the physical and mental well-being. Our findings are in accordance with the findings of Currie et al. (2), which systematize the most recent literature data related to DM and QOL. One study conducted in Korea using a EQ-5D-3L questionnaire emphasized age as an important parameter that determines the quality of life in patients with type 2 diabetes (18). In this study, younger patients reported a better quality of life, most likely due to the shorter duration of disease and fewer complications. These results are in accordance with findings of the study by Redekop et al. (23).

Our results demonstrate that employment has a significant association with higher PCS, MCS and EuroQoL VAS score which can be explained by higher incomes, improved economic status and less possibility for the occurrence of depressive mood. The same situation has been established in patients who have finished high school or have pre-university degree, while patients without formal 
Table 2. Macrovascular and microvascular complications of the study population $(N=285)$

\begin{tabular}{|c|c|c|c|c|}
\hline \multicolumn{3}{|l|}{ Complications } & & $\mathrm{n}(\%)$ \\
\hline \multirow{18}{*}{ Macrovascular } & \multirow{6}{*}{ Cardiovascular } & \multirow{2}{*}{ Angina pectoris } & yes & $57(20.0)$ \\
\hline & & & no & $228(80.0)$ \\
\hline & & \multirow{2}{*}{ Myocardial infarction } & yes & $42(14.7)$ \\
\hline & & & no & $243(85.3)$ \\
\hline & & \multirow{2}{*}{ Hearth failure } & yes & $35(12.3)$ \\
\hline & & & no & $250(87.7)$ \\
\hline & & \multirow{2}{*}{ TIA } & yes & $3(1.1)$ \\
\hline & & & no & $282(98.9)$ \\
\hline & Cerehrovascular & \multirow{2}{*}{ Stroke } & yes & $14(4.9)$ \\
\hline & Ceredrovascular & & no & $271(95.1)$ \\
\hline & & \multirow{2}{*}{ Cerebral infarct with residua } & yes & $12(4.2)$ \\
\hline & & & no & $273(95.8)$ \\
\hline & \multirow{6}{*}{ Peripheral vascular } & \multirow{2}{*}{ Oclusions } & yes & $37(13.0)$ \\
\hline & & & no & $248(87.0)$ \\
\hline & & \multirow{2}{*}{ Foot ulcer } & yes & $9(3.2)$ \\
\hline & & & no & $276(96.8)$ \\
\hline & & \multirow{2}{*}{ Amputations } & yes & $12(4.2)$ \\
\hline & & & no & $273(95.8)$ \\
\hline \multirow{12}{*}{ Microvascular } & \multirow{2}{*}{ Neurological } & \multirow{2}{*}{ Diabetes polyneuropathy } & yes & $211(74.0)$ \\
\hline & & & no & $74(26.0)$ \\
\hline & \multirow{4}{*}{ Nephrological } & \multirow{2}{*}{ Diabetes nephropathy } & yes & $40(14.0)$ \\
\hline & & & no & $245(86.0)$ \\
\hline & & \multirow{2}{*}{ Dialisis } & yes & $3(1.4)$ \\
\hline & & & no & $282(98.6)$ \\
\hline & \multirow{6}{*}{ Ophtalmological } & \multirow{2}{*}{ Diabetes retinopathy } & yes & $181(63.5)$ \\
\hline & & & no & $104(36.5)$ \\
\hline & & \multirow{2}{*}{ One eye blindness } & yes & $3(1.1)$ \\
\hline & & & no & $282(98.9)$ \\
\hline & & \multirow{2}{*}{ Both eye blindness } & yes & $1(0.4)$ \\
\hline & & & no & $284(99.6)$ \\
\hline
\end{tabular}

education have lower QOL. Various mechanisms could explain the interaction between lower QOL and lower level of education. They include inferior access to healthcare services, inadequate treatment plans and greater difficulties in adopting healthy habits, poorer mental health, and higher frequency of complications after diagnosis. From a clinical perspective, better management of these chronic conditions among individuals with lower educational level and/or unemployed individuals seems like the most appropriate intervention to reduce inequalities in HRQOL.

Patients with diabetes mellitus are more susceptible to microand macrovascular complications. According to estimates of the American Diabetes Association, about $75-80 \%$ of adult patients with DM will ultimately die from cardiovascular disease due to chronic macrovascular complications (24). It is generally known that long-term complications, especially microvascular, are connected to poor glycaemic control. Hence, even minor presence of diabetic complications has a significant impact on the QOL assessed using the SF-36 questionnaire (25). In addition, these complications represent a great burden for healthcare system, especially in some small developing countries. Univariate multiple regression analysis of the presence of micro- and macrovascular complications of DM showed that angina pectoris, heart failure, diabetic retinopathy, and diabetic nephropathy are the most important factors affecting the QOL in our population group.
After putting all these variables in multivariate model, they still remained statistically significant. The presence and number of diabetic complications showed significant effect on the QOL of patients with DM in numerous studies $(26,27)$. All these studies that analysed complications as a risk factor confirmed their significant negative impact. The link between the presence of coronary artery disease, particularly angina pectoris, with worse scores in all segments of SF-36 questionnaire was confirmed in many studies $(6,10-12)$. The study conducted by Lloyd et al. showed that coronary heart-disease is usually connected with a significant reduction in QOL, particularly in the area of physical health (28). At the same time, the study found a significant relationship between peripheral vascular disease and physical domains in particular, which the authors explained as the impact of complications on the patient lifestyle. Similar results regarding the presence of microvascular complications were confirmed in our population. Further, it is interesting to note that the analysed group had a high incidence of retinopathy, which indicates that this complication has a profound effect on patients' QOL.

We must mention some limitations of our study. First, this is a self-reported study, therefore, the patients' information about some conditions may be over- or underreported. Also, we do not have information about the severity of these complications. Meanwhile, the trained medical professionals who conducted 
Table 3. Univariate linear regression of socio-demographic variables on PCS, MCS and EQ-5D VAS

\begin{tabular}{|c|c|c|c|c|c|c|c|}
\hline \multirow{2}{*}{\multicolumn{2}{|c|}{ Variable }} & \multicolumn{2}{|c|}{ PCS } & \multicolumn{2}{|c|}{ MCS } & \multicolumn{2}{|c|}{ EQ-5D VAS } \\
\hline & & Beta & $\mathrm{p}$ & Beta & $\mathrm{p}$ & Beta & $\mathrm{p}$ \\
\hline \multicolumn{2}{|c|}{ Sex (reference group: male) } & -0.070 & 0.243 & -0.064 & 0.285 & -0.077 & 0.196 \\
\hline \multicolumn{2}{|l|}{ Age } & -0.365 & $<0.001$ & -0.302 & $<0.001$ & -0.267 & $<0.001$ \\
\hline \multicolumn{2}{|c|}{ Place of residence (reference group: city) } & -0.186 & 0.002 & -0.186 & 0.037 & -0.165 & 0.005 \\
\hline \multirow{5}{*}{ Education } & No formal education & -0.227 & $<0.001$ & -0.218 & $<0.001$ & -0.128 & 0.033 \\
\hline & Primary & -0.063 & 0.296 & -0.066 & 0.272 & -0.015 & 0.807 \\
\hline & High school & 0.151 & 0.011 & 0.139 & 0.020 & 0.038 & 0.523 \\
\hline & Pre-university & 0.155 & 0.009 & 0.129 & 0.030 & 0.135 & 0.024 \\
\hline & University & 0.047 & 0.463 & 0.092 & 0.123 & 0.033 & 0.586 \\
\hline \multirow{5}{*}{ Employment } & Employed & 0.237 & $<0.001$ & 0.181 & 0.002 & 0.155 & 0.009 \\
\hline & Unemployed & 0.085 & 0.154 & 0.089 & 0.135 & 0.071 & 0.232 \\
\hline & Farmer & -0.023 & 0.695 & -0.041 & 0.487 & 0.011 & 0.859 \\
\hline & Retirement & -0.212 & $<0.001$ & -0.150 & 0.011 & -0.144 & 0.015 \\
\hline & Invalid & -0.070 & 0.263 & -0.067 & 0.262 & -0.080 & 0.178 \\
\hline \multirow{4}{*}{ Marital status } & Unmarried & 0.046 & 0.437 & 0.080 & 0.178 & 0.046 & 0.441 \\
\hline & Married & 0.052 & 0.381 & 0.049 & 0.407 & 0.009 & 0.878 \\
\hline & Divorced & -0.051 & 0.395 & 0.064 & 0.282 & 0.070 & 0.243 \\
\hline & Widowed & -0.102 & 0.087 & -0.121 & 0.059 & -0.061 & 0.302 \\
\hline \multirow{4}{*}{ Economic status } & Poor & -0.156 & 0.008 & -0.126 & 0.033 & -0.140 & 0.018 \\
\hline & Fair & 0.055 & 0.358 & 0.001 & 0.990 & 0.078 & 0.193 \\
\hline & Good & 0.127 & 0.033 & 0.158 & 0.008 & 0.076 & 0.202 \\
\hline & Very good & 0.049 & 0.414 & 0.077 & 0.196 & 0.024 & 0.689 \\
\hline
\end{tabular}

PCS - Physical Component Score, MCS - Mental Component Score, EQ-5D VAS - EuroQol-5D VAS

Table 4. Multivariate linear regression of socio-demographic variables on PCS, MCS and EQ-5D VAS

\begin{tabular}{|c|c|c|c|c|c|c|c|}
\hline \multirow{2}{*}{\multicolumn{2}{|c|}{ Variable }} & \multicolumn{2}{|c|}{ PCS } & \multicolumn{2}{|c|}{ MCS } & \multicolumn{2}{|c|}{ EQ-5D VAS } \\
\hline & & Beta & $\mathrm{p}$ & Beta & $\mathrm{p}$ & Beta & p \\
\hline \multicolumn{2}{|l|}{ Age } & 0.339 & $<0.001$ & -0.280 & $<0.001$ & -0.289 & $<0.001$ \\
\hline \multicolumn{2}{|c|}{ Place of residence (reference group: city) } & -0.102 & 0.077 & -0.039 & 0.521 & -0.122 & 0.047 \\
\hline \multirow{3}{*}{ Education } & No formal education & -0.071 & 0.242 & -0.095 & 0.133 & -0.009 & 0.892 \\
\hline & High school & 0.163 & 0.211 & 0.139 & 0.106 & - & - \\
\hline & Pre-university & 0.155 & $<0.001$ & 0.122 & $<0.001$ & 0.138 & $<0.001$ \\
\hline \multirow{2}{*}{ Employment } & Employed & 0.027 & 0.669 & 0.008 & 0.899 & 0.006 & 0.933 \\
\hline & Retirement & -0.063 & 0.370 & -0.029 & 0.697 & -0.028 & 0.708 \\
\hline Marital status & Widowed & -0.008 & 0.885 & -0.029 & 0.627 & -0.010 & 0.869 \\
\hline \multirow{2}{*}{ Economic status } & Poor & -0.194 & $<0.001$ & -0.149 & $<0.001$ & -0.180 & $<0.001$ \\
\hline & Good & 0.056 & 0.320 & 0.102 & 0.083 & - & - \\
\hline
\end{tabular}

PCS - Physical Component Score, MCS - Mental Component Score, EQ-5D VAS - EuroQol-5D VAS

this survey provide assurance that medical conditions were appropriately recognized and well-classified. The advantage of our study is the use of multiple quality of measures.

\section{CONCLUSION}

The emphasized social and economic conditions, together with long-term complications, represent the root cause for many health problems. The results of this study show that both socioeconomic and chronic complications are relevant factors of HRQOL in diabetes mellitus patients. Age, residence in the rural areas, retirement, lower level of education and low socioeconomic status, as well as DM complications (angina pectoris, hearth failure, diabetes nephropathy, and diabetes retinopathy) were found to be independent risk factors for both component scores of SF-36 and EQ-VAS score in our study. Given the results, we suggest that health practitioners should be aware not only of the clinical parameters of patients with DM, but also of their educational level and working status. 
Table 5. Univariate linear regression of diabetes mellitus complications on PCS, MCS and EQ-5D VAS

\begin{tabular}{|l|c|c|c|c|c|c|}
\hline \multirow{2}{*}{ Complications } & \multicolumn{2}{|c|}{ PCS } & \multicolumn{3}{c|}{ MCS } & \multicolumn{2}{c|}{ EQ-5D VAS } \\
\cline { 2 - 7 } & Beta & $p$ & Beta & $p$ & Beta & \multicolumn{2}{c|}{$p$} \\
\hline Angina pectoris & -0.293 & $<0.001$ & -0.174 & $<0.001$ & -0.162 & $<0.001$ \\
\hline Myocardial infarction & 0.040 & 0.503 & 0.091 & 0.126 & 0.055 & 0.355 \\
\hline Hearth failure & 0.157 & $<0.001$ & 0.202 & $<0.001$ & 0.132 & 0.026 \\
\hline Transient ischaemic attack & -0.056 & 0.349 & -0.018 & 0.758 & -0.090 & 0.132 \\
\hline Stroke & -0.081 & 0.173 & -0.071 & 0.234 & -0.042 & 0.481 \\
\hline Cerebral infarction with residua & -0.024 & 0.688 & 0.018 & 0.765 & 0.017 & 0.777 \\
\hline Occlusions & -0.021 & 0.302 & -0.053 & 0.376 & -0.102 & 0.085 \\
\hline Foot ulcer & 0.083 & 0.163 & 0.114 & 0.055 & 0.035 & 0.561 \\
\hline Amputations & -0.015 & 0.801 & -0.015 & 0.801 & -0.048 & 0.424 \\
\hline Diabetes polyneuropathy & -0.055 & 0.351 & 0.031 & 0.597 & -0.083 & 0.165 \\
\hline Diabetes nephropathy & -0.132 & 0.026 & -0.111 & 0.062 & -0.167 & 0.005 \\
\hline Dialysis & -0.072 & 0.224 & -0.096 & 0.105 & -0.072 & 0.227 \\
\hline Diabetes retinopathy & -0.231 & $<0.001$ & -0.202 & 0.001 & -0.218 & $<0.001$ \\
\hline One eye blindness & -0.042 & 0.476 & 0.021 & 0.727 & 0.016 & 0.794 \\
\hline Both eye blindness & -0.060 & 0.311 & -0.068 & 0.255 & -0.073 & 0.222 \\
\hline
\end{tabular}

PCS - Physical Component Score, MCS - Mental Component Score, EQ-5D VAS- EuroQol-5D VAS

Table 6. Multivariate linear regression of diabetes mellitus complications on PCS, MCS and EQ-5D VAS

\begin{tabular}{|l|c|c|c|c|c|c|}
\hline \multirow{2}{*}{ Complications } & \multicolumn{2}{|c|}{ PCS } & \multicolumn{2}{|c|}{ MCS } & \multicolumn{2}{c|}{ EQ-5D VAS } \\
\cline { 2 - 8 } & Beta & $p$ & Beta & $p$ & Beta & $p$ \\
\hline Angina pectoris & -0.205 & $<0.001$ & -0.152 & 0.008 & -0.125 & 0.032 \\
\hline Hearth failure & 0.144 & 0.011 & 0.98 & 0.001 & 0.127 & 0.026 \\
\hline Diabetes nephropathy & -0.125 & 0.025 & - & - & -0.129 & 0.027 \\
\hline Diabetes retinopathy & -0.228 & $<0.001$ & -0.205 & $<0.001$ & -0.223 & $<0.001$ \\
\hline
\end{tabular}

PCS - Physical Component Score, MCS - Mental Component Score, EQ-5D VAS- EuroQol-5D VAS

\section{Adherence to Ethical Standards}

The study was approved by the Ethics Committee of the General Hospital of the city of Leskovac (4178/2, of 29 May 2015).

\section{REFERENCES}

1. Wild S, Roglic G, Green A, Sicree R, King H. Global prevalence of diabetes: estimates for the year 2000 and projections for 2030. Diabetes Care. 2004 May;27(5):1047-53.

2. Currie CJ, Peyrot M, Morgan CL, Poole CD, Jenkins-Jones S, Rubin RR, et al. The impact of treatment noncompliance on mortality in people with type 2 diabetes. Diabetes Care. 2012 Jun;35(6):1279-84.

3. Saito I, Inami F, Ikebe T, Moriwaki C, Tsubakimoto A, Yonemasu K, et al. Impact of diabetes on health-related quality of life in a population study in Japan. Diabetes Res Clin Pract. 2006 Jul;73(1):51-7.

4. Scollan-Koliopoulos M, Bleich D, Rapp KJ, Wong P, Hofmann CJ, Raghuwanshi M. Health-related quality of life, disease severity, and anticipated trajectory of diabetes. Diabetes Educ. 2013 Jan-Feb;39(1):83-91.

5. Oguntibeju OO, Odunaiya N, Oladipo B, Truter EJ. Health behaviour and quality of life of patients with type 2 diabetes attending selected hospitals in south western Nigeria. West Indian Med J. 2012 Sep;61(6):619-26.

6. Zanuso S, Balducci S, Jimenez A. Physical activity, a key factor to quality of life in type 2 diabetic patients. Diabetes Metab Res Rev. 2009 Sep;25 Suppl 1:S24-8.

7. Wong CK, Lo YY, Wong WH, Fung CS. The associations of body mass index with physical and mental aspects of health-related quality of life in Chinese patients with type 2 diabetes mellitus: results from a cross- sectional survey. Health Qual Life Outcom. 2013 Aug 21;11:142. doi: 10.1186/1477-7525-11-142.

8. Bourdel-Marchasson I, Druet C, Helmer C, Eschwege E, Lecomte P, LeGoff M, et al. Correlates of health-related quality of life in French people with type 2 diabetes. Diabetes Res Clin Pract. 2013 Aug;101(2):226-35.

9. Ali MK, Feeney P, Hire D, Simmons DL, O'Connor PJ, Ganz-Lord F, et al. Glycaemia and correlates of patient-reported outcomes in ACCORD trial participants. Diabet Med. 2012 Jul;29(7):e67-74.

10. Aguilar D, Solomon SD, Kober L, Rouleau JL, Skali H, McMurray JJ, et al. Newly diagnosed and previously known diabetes mellitus and 1-year outcomes of acute myocardial infarction: the VALsartan In Acute myocardial iNfarcTion (VALIANT) trial. Circulation. 2004 Sep 21;110(12):1572-8.

11. Zimbudzi E, Lo C, Ranasinha S, Gallagher M, Fulcher G, Kerr PG, et al. Predictors of health-related quality of life in patients with co-morbid diabetes and chronic kidney disease. PloS One. 2016;11(12):e0168491. doi: 10.1371/journal.pone.0168491.

12. Pedras S, Carvalho R, Pereira Mda G. Sociodemographic and clinical characteristics of patients with diabetic foot ulcer. Rev Assoc Med Brasil (1992). 2016 Apr;62(2):171-8.

13. Galer BS, Gianas A, Jensen MP. Painful diabetic polyneuropathy: epidemiology, pain description, and quality of life. Diabetes Res Clin Pract. $2000 \mathrm{Feb} ; 47(2): 123-8$.

14. Trikkalinou A, Papazafiropoulou AK, Melidonis A. Type 2 diabetes and quality of life. World J Diabetes. 2017 Apr 15;8(4):120-9.

15. Garratt AM, Ruta DA, Abdalla MI, Buckingham JK, Russell IT. The SF36 health survey questionnaire: an outcome measure suitable for routine use within the NHS? BMJ. 1993 May 29;306(6890):1440-4.

16. Herdman M, Gudex C, Lloyd A, Janssen M, Kind P, Parkin D, et al. Development and preliminary testing of the new five-level version of EQ-5D (EQ-5D-5L). Qual Life Res. 2011 Dec;20(10):1727-36. 
17. Feng Y, Parkin D, Devlin NJ. Assessing the performance of the EQ-VAS in the NHS PROMs programme. Qual Life Res. 2014 Apr;23(3):977-89.

18. Lee WJ, Song KH, Noh JH, Choi YJ, Jo MW. Health-related quality of life using the EuroQol 5D questionnaire in Korean patients with type 2 diabetes. J Korean Med Sci. 2012 Mar;27(3):255-60.

19. Rabin R, de Charro F. EQ-5D: a measure of health status from the EuroQol Group. Ann Med. 2001 Jul;33(5):337-43.

20. Bierman AS, Dunn JR. Swimming upstream. Access, health outcomes, and the social determinants of health. J Gen Intern Med. 2006 Jan;21(1):99-100.

21. Walker RJ, Gebregziabher M, Martin-Harris B, Egede LE. Independent effects of socioeconomic and psychological social determinants of health on self-care and outcomes in Type 2 diabetes. Gen Hosp Psychiatry. 2014 Nov-Dec;36(6):662-8.

22. Joensen LE, Almdal TP, Willaing I. Type 1 diabetes and living without a partner: psychological and social aspects, self-management behaviour, and glycaemic control. Diabetes Res Clin Pract. 2013 Sep;101(3):278-85.

23. Redekop WK, Koopmanschap MA, Stolk RP, Rutten GE, Wolffenbuttel BH, Niessen LW. Health-related quality of life and treatment satisfaction in Dutch patients with type 2 diabetes. Diabetes Care. 2002 Mar;25(3):458-63.
24. American Diabetes Association. Peripheral arterial disease in people with diabetes. Diabetes Care. 2003 Dec;26(12):3333-41.

25. Rasekaba TM, Graco M, Risteski C, Jasper A, Berlowitz DJ, Hawthorne $\mathrm{G}$, et al. Impact of a diabetes disease management program on diabetes control and patient quality of life. Popul Health Manag. 2012 Feb;15(1):12-9.

26. Quah JH, Luo N, Ng WY, How CH, Tay EG. Health-related quality of life is associated with diabetic complications, but not with short-term diabetic control in primary care. Ann Acad Med Singapore. 2011 Jun;40(6):276-86.

27. Jacobson AM, Braffett BH, Cleary PA, Gubitosi-Klug RA, Larkin ME. The long-term effects of type 1 diabetes treatment and complications on health-related quality of life: a 23-year follow-up of the Diabetes Control and Complications/Epidemiology of Diabetes Interventions and Complications cohort. Diabetes Care. 2013 Oct;36(10):3131-8.

28. Lloyd A, Sawyer W, Hopkinson P. Impact of long-term complications on quality of life in patients with type 2 diabetes not using insulin. Value Health. 2001 Sep-Oct;4(5):392-400.

Received December 28, 2016 Accepted in revised form May 14, 2018 